\title{
Nitrous oxide induced subacute combined degeneration with longitudinally extensive myelopathy with inverted V-sign on spinal MRI: a case report and literature review
}

\author{
Jun Liang Yuan', Shuang Kun Wang ${ }^{2}$, Tao Jiang ${ }^{2^{*}}$ and Wen Li Hu${ }^{1^{*}}$
}

\begin{abstract}
Background: Nitrous oxide (N2O), a long-standing anesthetic, is also neurotoxic by interfering with the bioavailability of vitamin B12 if abused. A few case studies have reported the neurological and psychiatric complications of N2O.

Case presentation: Here, we reported a patient of N2O induced subacute combined degeneration (SCD) with longitudinally extensive myelopathy with inverted $V$-sign exhibiting progressive limb paresthesia and unsteady gait.

Conclusions: This case raises the awareness of an important mechanism of neural toxicity of $\mathrm{N} 2 \mathrm{O}$, and clinical physicians should be well recognized this in the field of substance-related disorders.
\end{abstract}

Keywords: Nitrous oxide, Subacute combined degeneration

\section{Background}

Nitrous oxide (N2O) is a long-standing anesthetic, which also has neurotoxicity by interfering in the bioavailability of vitamin B12 if abused. A few case studies have reported the neurological and psychiatrical complications, even death, related to $\mathrm{N} 2 \mathrm{O}$ abuse [1]. Among these complications, N2O-induced myelopathy has been regarded as the most common manifestation [1]. To the best of our knowledge, there are only 18 cases describing $\mathrm{N} 2 \mathrm{O}$-induced subacute combined degeneration (SCD); however, to date, only very rare cases with longitudinally extensive myelopathy with inverted V-sign or "rabbit ears" sign on spinal posterior column. We herein described a 20-year-old female who developed SCD with inverted V-sign on spinal column related to the abuse of $\mathrm{N} 2 \mathrm{O}$.

\section{Case presentation}

A 20-year-old woman presented with progressive paresthesia in her legs and hands, and unsteady gait for

* Correspondence: jiangtao@bjcyh.com; huwenli@sina.com

${ }^{2}$ Department of Radiology, Beijing Chaoyang Hospital, Capital Medical University, Beijing 100020, China

${ }^{1}$ Department of Neurology, Beijing Chaoyang Hospital, Capital Medical University, Beijing 100020, China
15 days. She had inhaled N2O about 100-200 whipped cream chargers many times daily, for recreational purposes for at least one year. Neuropsychological test showed mild impairment of the cognition, and the Mini mental state examination (MMSE) score was 23. The deficit domains of the MMSE included orientation (minus 3 scores), attention and calculation (minus 4 scores). Neurological examination revealed distal slight weakness, decreased vibration and proprioception, bilateral hyporeflexia, sensory ataxia, positive Babinski sign and Romberg sign.

Laboratory tests revealed decreased level of folic acid $(4.40 \mathrm{ng} / \mathrm{ml}$, reference range $>5.4 \mathrm{ng} / \mathrm{ml})$, but the others were normal, including red blood cell, hemoglobin, mean corpuscular volume, serum vitamin B12 $(800 \mathrm{pg} / \mathrm{ml}$, reference range $211-911 \mathrm{pg} / \mathrm{ml})$ and homocysteine $(8 \mu \mathrm{mmol} / \mathrm{L}$, reference range $0-15 \mu \mathrm{mol} /$ L). The antibodies of human immunodeficiency virus and neurosyphilis were negative. The results of cerebrospinal fluid test (CSF) were normal for leucocyte count $(5 / \mu \mathrm{L}$, reference range $0-8 / \mathrm{L})$, glucose $(3.1 \mathrm{mmol} / \mu \mathrm{L}$, reference range $2.5-4.5 \mathrm{mmol} / \mathrm{L})$, and protein concentration $(33 \mathrm{mg} / \mathrm{dl}$, reference range $15-45 \mathrm{mg} / \mathrm{dl})$. The 
inflammatory, immune and infectious biomarkers of both CSF and serum were also unremarkable.

The cranial MRI yielded normal findings. The spinal cord MRI showed abnormal longitudinally extensive T2 weighted hyperintensities involving the posterior columns from $\mathrm{C} 1$ through $\mathrm{T} 12$, with inverted $\mathrm{V}$ or "rabbit ears" sign on cervical spinal MRI, but without contrast enhancement (Figs. 1 and 2). Electromyography showed multiple peripheral neurogenic damage, also with decreased nerve conduction velocity and abnormal somatosensory evoked potential. However, visual evoked potential showed normal response.

Three months later, with a high dose of supplementation of intramuscular vitamin B12 injections (1 mg per day) and the cessation of $\mathrm{N} 2 \mathrm{O}$ exposure, the symptoms of sensation and gait resolved markedly, and the cognitive function fully recovered (MMSE 30). The abnormal hyperintensities of spinal MRI also dissolved with three months' follow up (Figs. 3 and 4). The diagnosis of $\mathrm{N} 2 \mathrm{O}$ induced SCD was supported by clinical history, clinical manifestations, MRI findings, the distinct relationship between $\mathrm{N} 2 \mathrm{O}$ exposure, also with the favorable prognosis by the vitamin B12 supplementation.

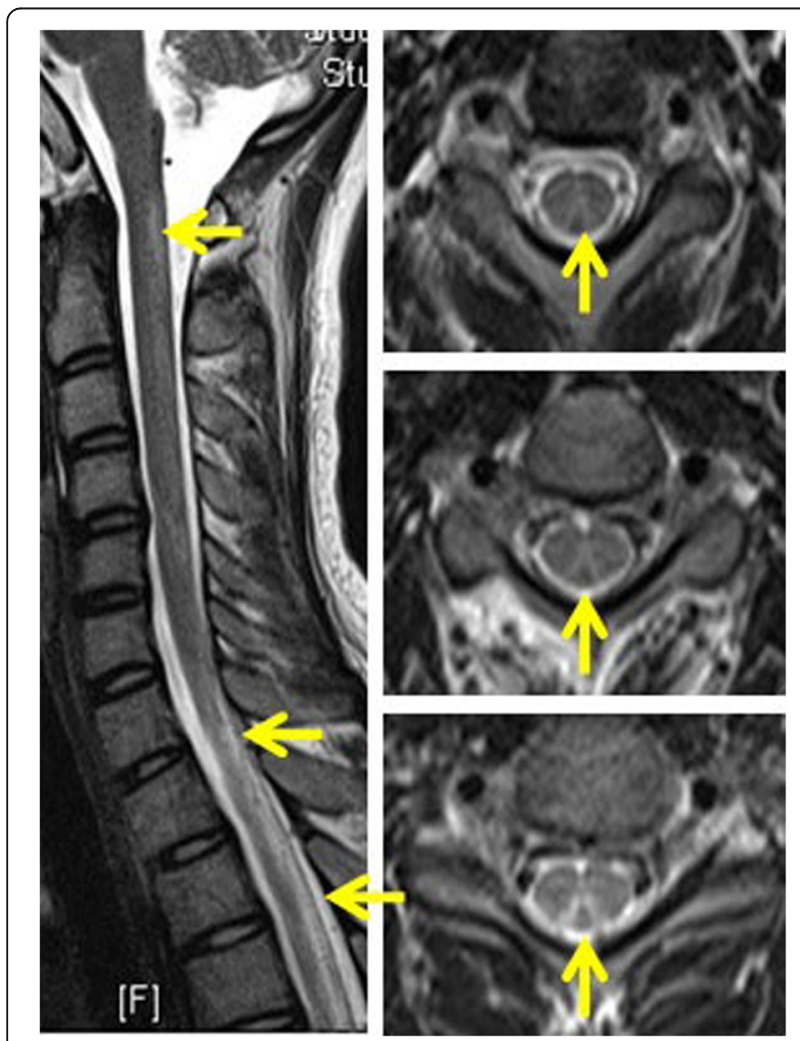

Fig. 1 The MRI of spinal cord disclosed abnormal hyperintensities within the dorsal cervical spinal cord. On axial series, V-shaped $\mathrm{T} 2$ hyperintensities were again noted within the dorsal cervical spinal cord

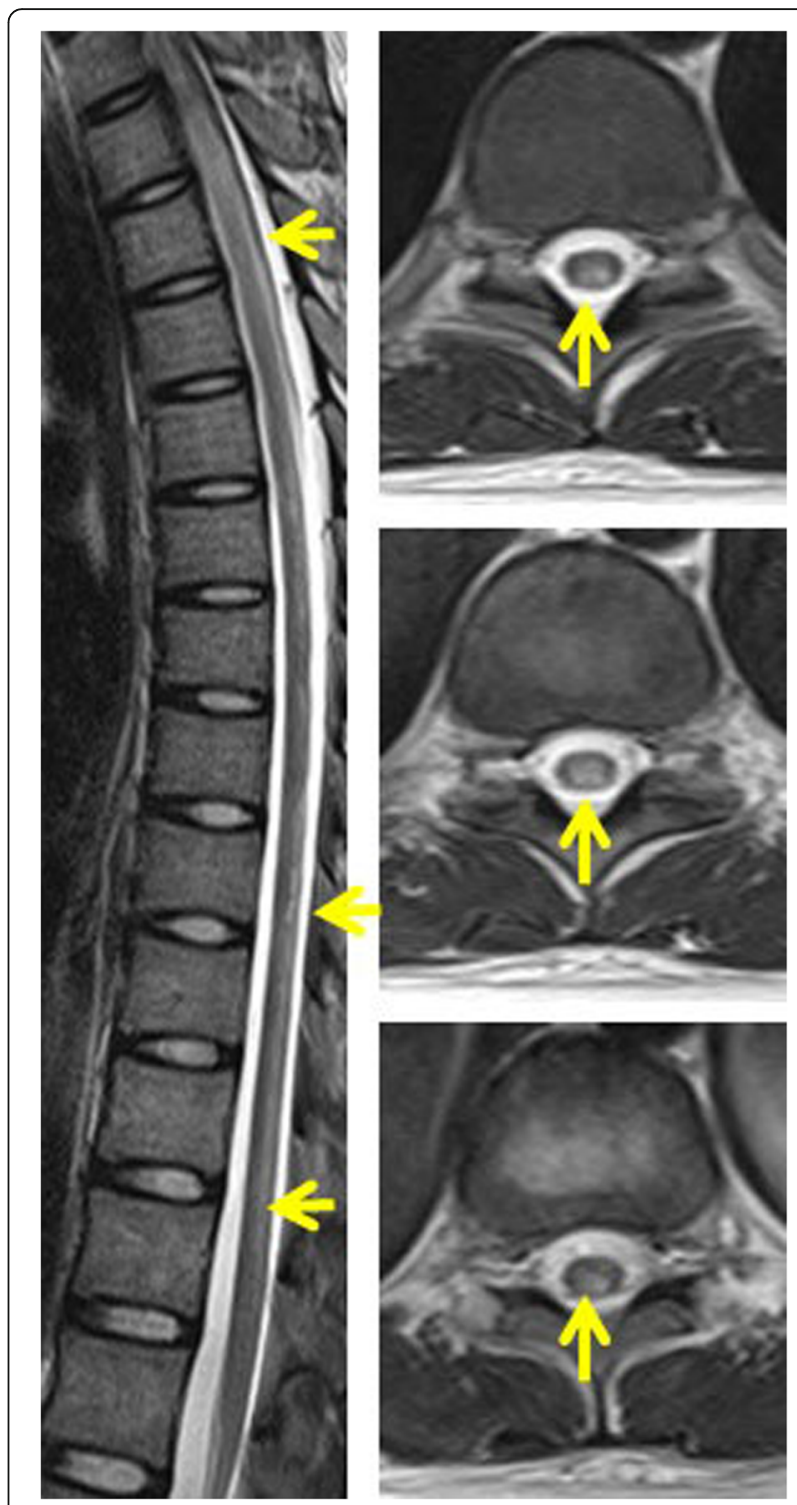

Fig. 2 The MRI of spinal cord showed abnormal hyperintensities within the dorsal thoracic spinal cord

\section{Discussion and conclusions}

$\mathrm{N} 2 \mathrm{O}$, a well-known anesthetic, has a long history for its recreational use, and its consumption is on the rise rapidly [2]. Several case studies have reported neurological and psychiatric complications of $\mathrm{N} 2 \mathrm{O}$ use [1]. To date, there are only 18 cases describing SCD caused by $\mathrm{N} 2 \mathrm{O}$ abuse. However, the exact mechanisms of SCD induced by $\mathrm{N} 2 \mathrm{O}$ have not been well elucidated. $\mathrm{N} 2 \mathrm{O}$ potentially interferes with methionine synthesis by inactivating methylcobalamin [3]. Except for the deficient methylation hypothesis, some other newly discovered functions of B12 in regulating cytokines and growth factors have also been raised [4]. 


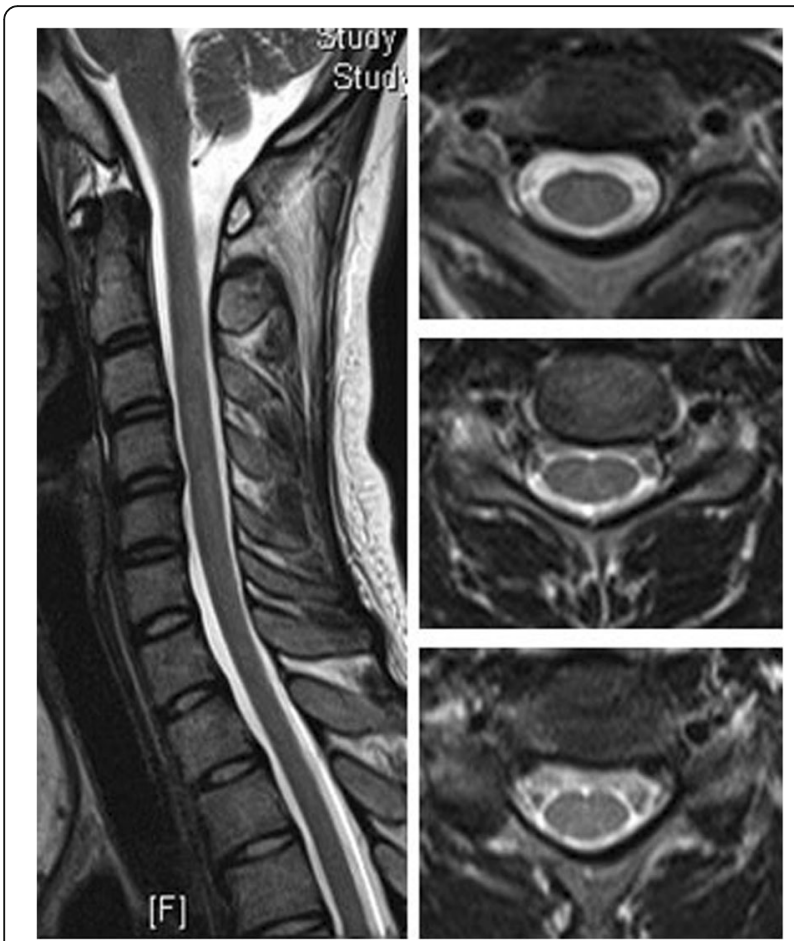

Fig. 3 Follow-up cervical spinal cord of MRI revealed the resolution of the previously noted lesions of inverted V-sign within the posterior columns

The strengths of our case were listed as follows. Firstly, our case revealed symmetric abnormal signal in the dorsal columns of the cervical and thoracic cord, especially with inverted V-sign on cervical spinal. To the best of our knowledge, only one case has been previously described of such longitudinally extensive myelopathy induced by $\mathrm{N} 2 \mathrm{O}$ [5]. Our case also indicated symmetric, reversible changes in the posterior columns correlating well with patients' clinical symptoms after vitamin B12 supplementation. Secondly, to the best of our knowledge, this is the first report about the coexistence of mild cognitive impairment in patient with SCD by $\mathrm{N} 2 \mathrm{O}$ abuse, in spite that the assessment of cognition was only measured by the MMSE. The underlying mechanism of cognitive decline may attributed to the neural toxicity of $\mathrm{N} 2 \mathrm{O}$ or the metabolic disturbances from the lower level of metabolites such as folic acid and vitamin B12 or hyperhomocysteinemia [6]. Thirdly, abuse of $\mathrm{N} 2 \mathrm{O}$ is common, but generally underestimated especially in developing countries. To date, this is also the first case reported in China (mainland).

In summary, the abuse of $\mathrm{N} 2 \mathrm{O}$ has some potentially serious outcomes, especially in young patients presenting with myelopathic symptoms of unclear aetiology [7]. N2O induced SCD may be a very rare manifestation associated with $\mathrm{N} 2 \mathrm{O}$ abuse. Early diagnosis and
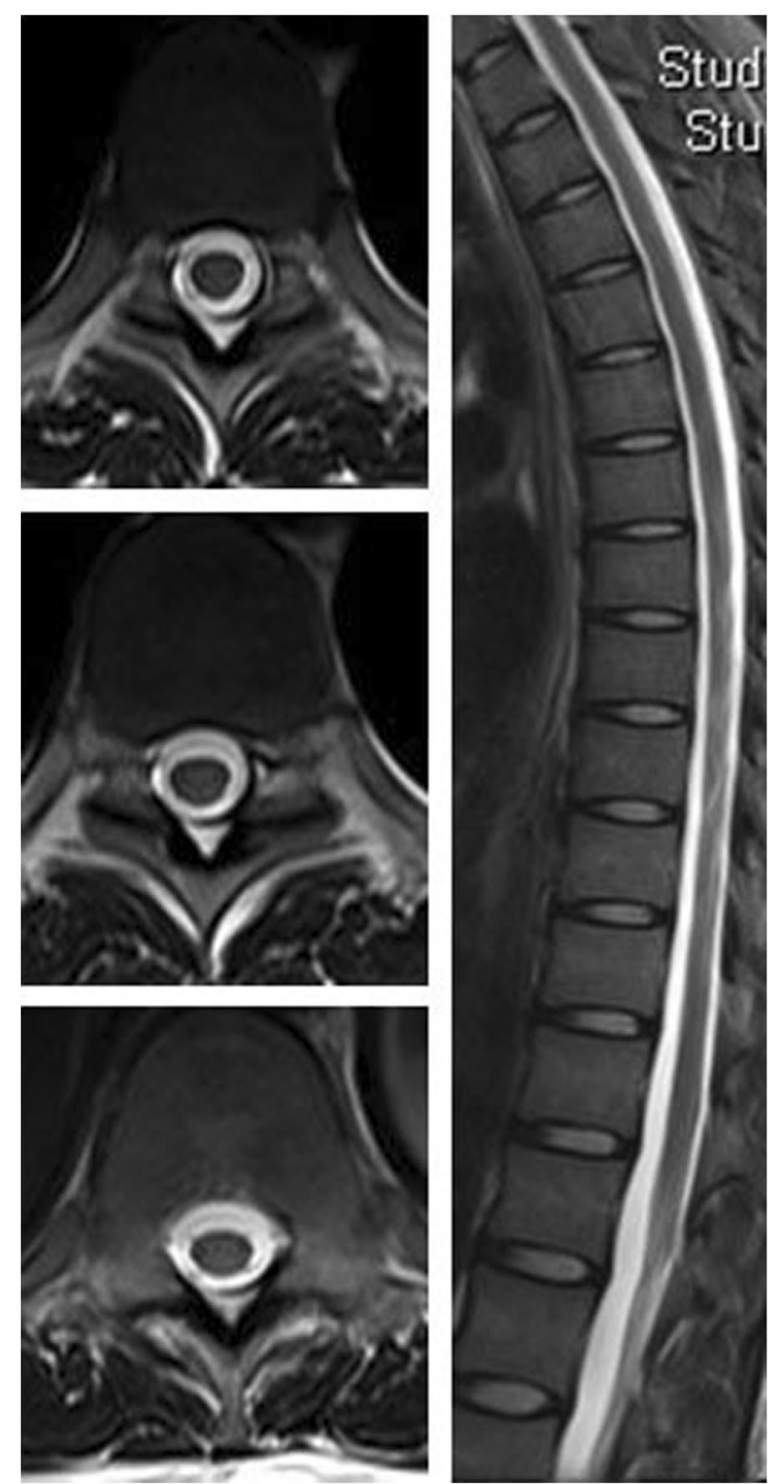

Fig. 4 Follow-up thoracic spinal cord of MRI showed significant remission of the posterior columns' signal alterations

treatment are crucial because it represents a treatable and potentially reversible cause of myelopathy with vitamin B12 [2]. Our case also raises awareness of an important complication of neural toxicity of $\mathrm{N} 2 \mathrm{O}$.

\section{Abbreviations}

CSF: Cerebrospinal fluid test; MMSE: Mini mental state examination; N2O: Nitrous oxide; SCD: Subacute combined degeneration

\section{Acknowledgements}

Not applicable

\section{Funding}

This work was supported by the National Natural Science Foundation of China (81301016) and the Beijing Municipal Administration of Hospitals' Youth Programme (QML20150303). 


\section{Availability of data and materials}

Not applicable

\section{Authors' contributions}

$J L Y$ examined, evaluated the patient and drafted the manuscript. SKW performed and interpreted the MRI studies. TJ and WLH participated in the design of the case-report and helped to draft the manuscript. All authors read and approved the final manuscript.

\section{Ethics approval and consent to participate}

The study was approved by the Institutional Ethical Committee of Beijing Chaoyang Hospital, Capital Medical University.

\section{Consent for publication}

Written informed consent was obtained from the patient for publication of this Case Report and any accompanying images. A copy of the written consent is available for review by the Editor of this journal.

\section{Competing interests}

The authors declare that they have no competing interests.

\section{Publisher's Note}

Springer Nature remains neutral with regard to jurisdictional claims in published maps and institutional affiliations.

Received: 20 May 2017 Accepted: 26 November 2017

Published online: 28 December 2017

\section{References}

1. Garakani A, Jaffe RJ, Savla D, Welch AK, Protin CA, Bryson EO, et al. Neurologic, psychiatric, and other medical manifestations of nitrous oxide abuse: a systematic review of the case literature. Am J Addict. 2016;25:358-69.

2. Mancke F, Kaklauskaite $G$, Kollmer J, Weiler M. Psychiatric comorbidities in a young man with subacute myelopathy induced by abusive nitrous oxide consumption: a case report. Subst Abuse Rehabil. 2016:7:155-9.

3. Garakani A, Welch AK, Jaffe RJ, Protin CA, McDowell DM. Psychosis and low cyanocobalamin in a patient abusing nitrous oxide and cannabis. Psychosomatics. 2014;55:715-9.

4. Hathout L, El-Saden S. Nitrous oxide-induced B(1)(2) deficiency myelopathy: perspectives on the clinical biochemistry of vitamin B12. J Neurol Sci. 2011;301:1-8.

5. Ernst LD, Brock K, Barraza LH, Davis A, Nirenberg MJ. Longitudinally extensive nitrous oxide Myelopathy with novel radiographic features. JAMA Neurol. 2015;72:1370-1.

6. Smith AD, Refsum H. Homocysteine, B Vitamins, and cognitive impairment Annu Rev Nutr. 2016:36:211-39.

7. Sotirchos ES, Saidha S, Becker D. Neurological picture. Nitrous oxide-induced myelopathy with inverted V-sign on spinal MRI. J Neurol Neurosurg Psychiatry. 2012;83:915-6.

\section{Submit your next manuscript to BioMed Central} and we will help you at every step:

- We accept pre-submission inquiries

- Our selector tool helps you to find the most relevant journal

- We provide round the clock customer support

- Convenient online submission

- Thorough peer review

- Inclusion in PubMed and all major indexing services

- Maximum visibility for your research

Submit your manuscript at www.biomedcentral.com/submit
Biomed Central 